\title{
Effect of immediate versus delayed loadings of dental implants on the oral health-related quality of life in Saudi population
}

\author{
Experimental clinical trial
}

Maha A. Bahammam, DSc, DABP, Wamiq M. Fareed, BDS, MDS.

\begin{abstract}
الأهداف : تقييم آثار التحميل الفوري والمتأخر للغرسات السنية على المي

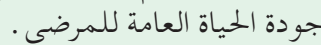

الطريقة : أجري التحليل للحالات التي أجريت في قسم عيادات

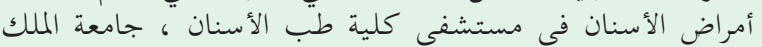

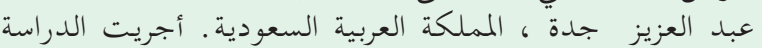

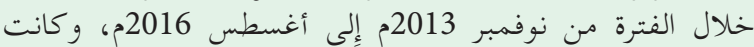

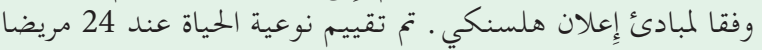

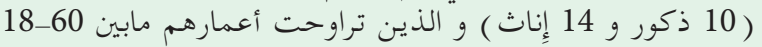

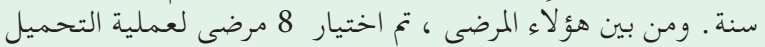

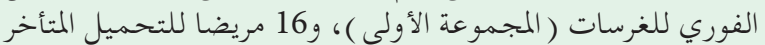

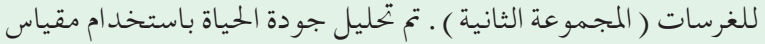
تقييم QoL قبل وبعد تحميل الغرسة.

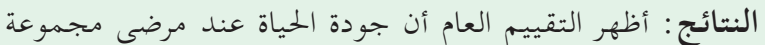

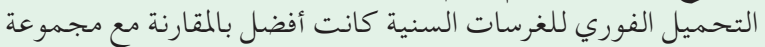

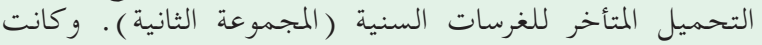

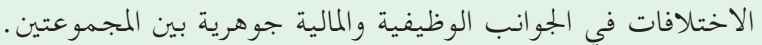

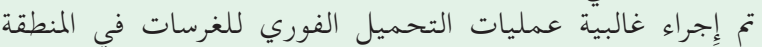
التجميلية الأمامية وكان لها تأثير كبير على جود دة الحياة .

الخاتمة : خلصت النتائج إلى أن التحميل الفوري للغرسات السنية

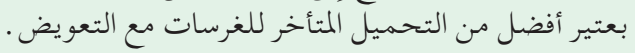

Objectives: To assess the effects of immediate and delayed loadings of dental implants on the overall quality of life (QoL) of patients.

Methods: The prospective analysis was conducted in the Department of Periodontology Clinics, Faculty of Dentistry Hospital, King Abdulaziz University, Jeddah, Kingdom of Saudi Arabia. The study was conducted from
November 2013 to August 2016 and was according to the principles of the Helsinki Declaration. Quality of life in 24 patients (10 males and 14 females), aged between 18-60 years were assessed. Among the patients, 8 were opted for immediate implant loading (Group I), while 16 have opted for delayed implant loading (Group II). The quality of life was analyzed using a QoL assessment scale before and after the implant loading.

Results: Overall assessment revealed that the QoL among the patients immediately after loading of dental implant (Group I) was better as compared to the delayed loading of dental implant (Group II). The differences of functional and financial aspects were significant between both groups. The majority of the immediate implant's loadings have been performed in the anterior aesthetic zone and has a significant impact on the QoL.

Conclusion: The results concluded that immediate loading of dental implant is better than the delayed loading of a dental implant with a prosthesis.

Saudi Med J 2019; Vol. 40 (1): 79-86 doi: 10.15537/smj.2019.1.23370

From the Department of Periodontology (Bahammam), Faculty of Dentistry, King Abdulaziz University, Jeddah, and from the Department of Oral \& Maxillofacial Surgery (Fareed), Faculty of Dentistry, Taibah University, Al-Madinah Al-Munawarah, Kingdom of Saudi Arabia.

Received 16th July 2018. Accepted 14th November 2018

Address correspondence and reprint request to: Dr. Maha A. Bahammam, Department of Periodontology, Faculty of Dentistry, King Abdulaziz University, Jeddah, Kingdom of Saudi Arabia. E-mail:mbahammam@kau.edu.sa

ORCID ID: orcid.org/0000-0001-9852-490X 
T he introduction of the osseo-integrated implant is considered as one of the greatest breakthroughs in the clinical dentistry. The treatment of replacing missing teeth with removable or fixed partial dentures was the only treatment before the advent of implants. Recently, numerous new dental implants have been developed. The latest treatment protocol for osseo-integrated implants includes an unloaded healing period of at least 3-6 months before the implantation of prosthetic superstructure and functional loading. ${ }^{1-4} \mathrm{~A}$ number of factors are needed to be considered, when treatment, planning, and management is carried out for a tooth; the periodontitis factors include the condition of pulpal and periodontal, tooth storability, bone quality, tooth color, and bone quantity as well as the condition of the soft tissues. ${ }^{5-7}$ Patient-related factors such as aesthetic demands, systemic, mental and oral health, ease and treatment perceptions. Treatment-related factors such as the perspective for procedural complications, costbenefit ratio, and the treatment outcomes. The term "health-related quality of life" is now extensively used and accepted worldwide. Interest and concern in the outcome of oral health problems have been the theme of significant research activity for nearly a decade. It is because the tooth loss can have detrimental effect on the life of the individuals, particularly psychological. These include loss of confidence in the individual, lack of interest towards formation of close relationship, hiding teeth or completely avoiding laughing in public, partially when the tooth loss is in anterior teeth. ${ }^{5}$ The dental implant plays a significant role in the replacement of single tooth especially when it is desirable to avoid involvement of the adjacent teeth that have no caries. The patient desires that their lost teeth should be replaced as early as possible to continue their normal life without any psychological trauma. The dental scientific community has given significant attention to the patient-centered outcomes and impact of oral rehabilitations on QoL. A recent study has shown that physical disability and functional limitation were significantly higher among the patients with delayed loading; whereas, social disability was significantly higher among the patients with immediate loading. ${ }^{6}$ Moreover, high functional limitation was reported in shorter follow-up that is less than 5 years. Another study has shown that immediate loading with fixed

Disclosure. This study was funded by the Deanship of Scientific Research (DSR), King Abdulaziz University, Jeddah, Saudi Arabie (Grant No. D1439-33-165). prosthesis within maxilla comes out to be a successful outcome based on the choice of implant and choice of surgical/prosthetic treatment. ${ }^{7}$ Considering this, the policymakers and oral healthcare professionals have recognized that the assessment of oral health outcomes plays a vital role in planning oral health care programs. The patient-based outcome measures play an important role in clinical decision making. Moreover, the clinicians and researchers require specific instruments for assessing the outcomes. The patients may be benefitted as a result of shift from clinical longevity towards the assessments of health status. It is significant for the clinicians to proof that measurement of health status plays an important role to improve patient care in providing services. Additionally, the existing study's focus is primarily confined to the study of bone density protocol, the aspect of QoL of patients remains a novel subject. ${ }^{8}$ Similarly, the previous studies followed a small time frame such as 6 months limiting the application of the study results. ${ }^{9}$ Therefore, the purpose of this planning is to review the current status of oral health QoL in the light of latest developments in the field. The present study has evaluated the immediate and delayed implant loading into the extracted site and its effect on the QoL in pre- and post-insertion period.

Hypothesis. $\mathrm{H}_{0}$ : There is a significant impact of immediate loadings of dental implants on the QoL. $\mathrm{H}_{1}$ : There is a significant impact of dental implants loadings of dental implants on the QoL. $\mathrm{H}_{2}$ : There is no impact of both the factors on the dental implants on the QoL.

Methods. The experimental study was conducted in the Department of Periodontology Clinics, Faculty of Dentistry Hospital, King Abdulaziz University, Jeddah, Kingdom of Saudi Arabia. The study was conducted from November 2013 to August 2016. The study recruited 24 patients (10 males and 14 females), aged between 18-60 years (Figure 1). The sample size was calculated on the basis of prospective random control studies.

The study has used power calculation to estimate the total number of respondents, who are likely to be included in the study. Among them, 8 opted for immediate implants loading (Group I), in which prosthesis is attached to the implants the same day the implants are placed. While, 16 opted for delayed implant loading (Group II), which is attached at a second procedure after a conventional healing period of 3-6 months. The baseline clinical examination consisted of thorough medical and dental history, general and oral health status, and assessment of the proposed implant site. The study has included 8 patients in Group I due 


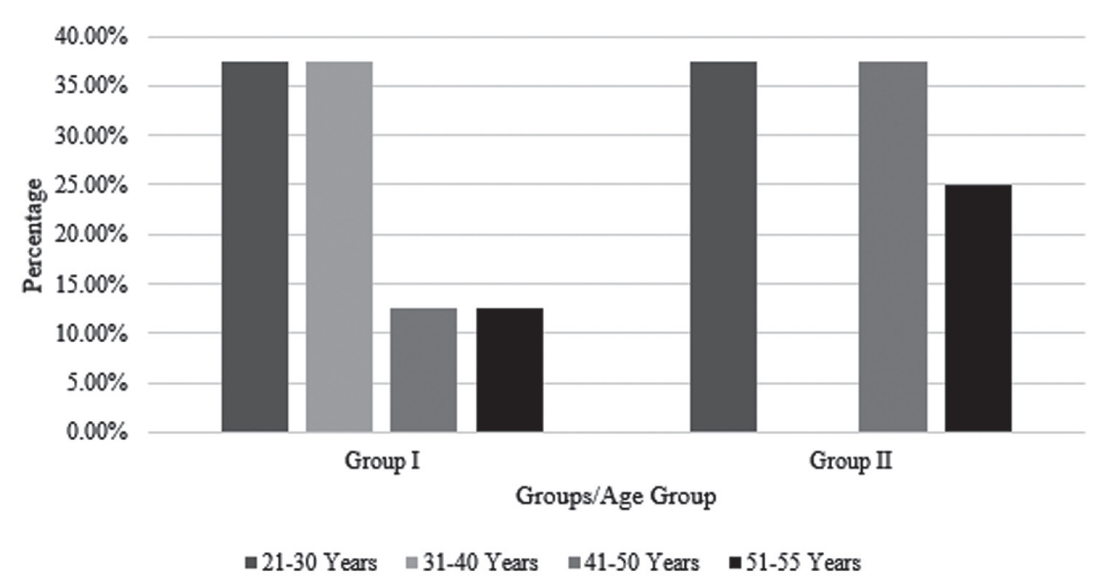

Figure 1 - Age-wise distribution of the study subjects.

to the unavailability of the data whereas 16 patients were included in the Group II due to the availability and accessibility of the data.

The study inclusion criteria involve individuals who had immediate loading of the implants data along with dental radiographs, as well as edentulous mandible with 2 implants placed in the anterior mandible. Patients with uncontrolled diabetes mellitus, irradiated bone, alcohol abuse, pregnancy, and psychological problems were excluded from the study. Informed consent was obtained from all study subjects before recruiting them in the study. All research procedures were explained to the patients, who provided signed consent to participate in the study. The pre- and post-treatment QoL oral and dental subscale (QoL-OS/DS) were assessed in both immediate and delayed loading dental implant patients after one month of undergoing the treatment.

Structure of the QoL dental subscale. The scale was divided into 4 parts, each addressing a particular aspect of the QoL. The detailed description of each part of the scale is as follows: functional; the functional QoL addresses the functional needs of the patient related to the dental ailment. It analyzes the ability of a patient to perform all the functions related to the use of teeth. This includes 5 items, which are intended to evaluate the ability to take all kinds of food, ability to speak some particular words/phonetics, ability to speak some specific foodstuff, ability to clean teeth/ prosthesis properly, and ability to use opposing tooth effectively. Social: This section analyzes the issues related to the effect of dental ailment on the social QoL of an individual. The 5 items under this section include unwanted attention towards the missing tooth, reduction in participation in social gatherings, avoidance by spouse/partner, recommendations to visit a dentist, and social contacts making fun. Psychological: when the functional and social life of an individual is affected, it obviously affects the psychology. Quality of life OS/ DS developed by the author incorporates 5 items to address the psychological QoL-related to the dental ailment. The 5 items are feeling of ugliness, covering mouth with hand/handkerchief, loss of confidence, continuous thinking about dental problem, and fear of hurting the gums. Financial: a physical ailment is also associated with financial issues. The cost of treatment, loss of work owing to the treatment schedule, and costs to make visits to a dentist contribute to the financial QoL. Quality of life OS/DS interprets the financial QoL through the expenditure on dental prosthesis, costs of visits to a dentist, costs of taking special diet, cost of oral care and dental hygiene, and cost of loss of occupational commitments.

Statistical analysis. The sum of all the scores obtained on QoL-OS/DS provided the information regarding the severity of the problem related to the QoL as encountered by the patient. The pretreatment administration of QoL highlighted the post treatment administration of QOL-OS/DS provided the information about the treatment, impact, and the treatment gaps. This is determined by the differences between the pre-treatment and post-treatment scores on each aspect of the QoL. The QoL-OS/DS scale was checked for its reliability and was found to be reliable, thus ensuring the internal consistency of the scale. The 
interpretation of scores was as follows: total score range: Inference:

0-20: no serious impact on the QoL

21-40: the QoL affected to a limited extent

41-60: the QoL affected to a certain extent

$>60$ : the QoL is severely affected.

For different sections, the interpretations of scores were as follows: section score range: Inference

0-5: no serious impact on the QoL

6-10: the QoL affected to a limited extent

11-15: the QoL affected to a certain extent

>15: the QoL severely affected.

The study has used Chi-square test to reveal the association between categorical variables. Mean and standard deviations are provided for each item while significance values are provided for the association between categorical items.

Results. The summary of QoL results showed that among the patients of Group II, the functional $(p=0.013)$ and financial $(p=0.013)$ QoL were affected more severely as compared to Group I patients. It indicated an urgent need for intervention in the Group II subjects related to the issues. Although, the mean scores for Group I subjects were lower than that of Group II subjects for all the aspects of QoL and the total scores. However, there was no significant difference observed between the 2 groups for the total scores $(p=0.077)$. After the treatment, the mean values did not reach the threshold value of 15 for any aspect in both groups. It indicated that after the treatment, the QoL of patients was normal. The overall assessment revealed that the QoL of Group I patients was better than that of Group II patients ( $p=0.033)$; however, only the differences in functional and financial aspects were significant between the 2 groups.

The findings of the study were assessing the statistically significant differences between 2 groups in terms of their ability to speak for specific foodstuff and ability to use opposing tooth efficiently. However, Group I subject showed higher scores as compared to Group II subjects (Table 1). After treatment, the QoL scores in Group I was found to be maximum for the items ability to use opposing tooth efficiently. The score

Table 1 - Functional, social, psychological, and financial quality of life (QoL) after treatment.

\begin{tabular}{|c|c|c|c|c|}
\hline \multirow[t]{2}{*}{ QoL aspects } & Group I $(n=8)$ & Group II $(n=16)$ & \multicolumn{2}{|c|}{ Statistical significance } \\
\hline & \multicolumn{2}{|c|}{ Mean \pm SD } & t & $P$-value \\
\hline \multicolumn{5}{|l|}{ Functional aspect } \\
\hline $\begin{array}{l}\text { Ability to take all kind of food } \\
\text { Disability to speak some particular words/phonetics } \\
\text { Ability to eat specific foodstuff } \\
\text { Ability to clean teeth/prosthesis properly } \\
\text { Ability to use opposing tooth efficiently } \\
\text { Total score }\end{array}$ & $\begin{array}{l}0.88 \pm 0.83 \\
1.63 \pm 1.06 \\
2.25 \pm 1.04 \\
1.13 \pm 1.25 \\
2.25 \pm 0.89 \\
8.13 \pm 3.44\end{array}$ & $\begin{array}{l}1.75 \pm 0.68 \\
2.25 \pm 1.13 \\
2.81 \pm 1.17 \\
2.00 \pm 1.21 \\
3.44 \pm 0.73 \\
12.25 \pm 1.57\end{array}$ & $\begin{array}{l}-2.750 \\
-1.306 \\
-1.153 \\
-1.653 \\
-3.509 \\
-4.081\end{array}$ & $\begin{array}{l}0.012 \\
0.205 \\
0.261 \\
0.113 \\
0.002 \\
0.000\end{array}$ \\
\hline \multicolumn{5}{|l|}{ Social aspect } \\
\hline $\begin{array}{l}\text { Unwanted attention towards missing tooth } \\
\text { Reduction in participation in social gatherings } \\
\text { Avoidance by spouse/partner } \\
\text { Recommendations to visit a dentist } \\
\text { Social contacts cutting jokes on missing tooth } \\
\text { Total score }\end{array}$ & $\begin{array}{c}2.38 \pm 1.06 \\
2.25 \pm 0.71 \\
1.50 \pm 1.31 \\
2.38 \pm 1.06 \\
2.38 \pm 0.52 \\
10.88 \pm 3.04\end{array}$ & $\begin{array}{c}3.31 \pm 0.95 \\
2.44 \pm 1.03 \\
1.38 \pm 0.96 \\
1.56 \pm 0.96 \\
1.75 \pm 0.93 \\
10.44 \pm 3.22\end{array}$ & $\begin{array}{r}-2.200 \\
-0.461 \\
0.267 \\
1.884 \\
1.755 \\
0.319\end{array}$ & $\begin{array}{l}0.039 \\
0.650 \\
0.792 \\
0.073 \\
0.093 \\
0.753\end{array}$ \\
\hline \multicolumn{5}{|l|}{ Psychological aspect } \\
\hline $\begin{array}{l}\text { Feeling of ugliness } \\
\text { Covering mouth with hand/handkerchief } \\
\text { Loss of confidence } \\
\text { Continuous thinking about missing tooth } \\
\text { Fear of hurting gums } \\
\text { Total score }\end{array}$ & $\begin{array}{c}1.88 \pm 1.25 \\
2.13 \pm 1.25 \\
2.38 \pm 0.74 \\
2.13 \pm 0.64 \\
2.75 \pm 1.16 \\
11.25 \pm 3.88\end{array}$ & $\begin{array}{l}2.63 \pm 1.20 \\
3.00 \pm 0.63 \\
2.38 \pm 1.31 \\
2.50 \pm 0.97 \\
2.38 \pm 1.67 \\
12.88 \pm 3.58\end{array}$ & $\begin{array}{r}-1.422 \\
-2.307 \\
0.000 \\
-0.989 \\
0.567 \\
-1.021\end{array}$ & $\begin{array}{l}0.169 \\
0.031 \\
1.000 \\
0.333 \\
0.576 \\
0.318\end{array}$ \\
\hline \multicolumn{5}{|l|}{ Financial aspect } \\
\hline $\begin{array}{l}\text { Expenditure on dental prosthesis } \\
\text { Cost of visits to a dentist } \\
\text { Cost of taking special diets } \\
\text { Cost of oral care and maintenance of oral hygiene } \\
\text { Cost of loss of occupational commitments } \\
\text { Total score }\end{array}$ & $\begin{array}{l}0.75 \pm 1.49 \\
1.63 \pm 1.77 \\
1.13 \pm 1.25 \\
2.13 \pm 1.25 \\
2.13 \pm 0.64 \\
7.75 \pm 3.01\end{array}$ & $\begin{array}{c}1.50 \pm 1.55 \\
2.81 \pm 0.40 \\
2.06 \pm 1.44 \\
2.94 \pm 0.85 \\
2.13 \pm 1.15 \\
11.44 \pm 3.37\end{array}$ & $\begin{array}{c}-1.132 \\
-2.609 \\
-1.570 \\
-1.884 \\
0.000 \\
-2.614\end{array}$ & $\begin{array}{l}0.270 \\
0.016 \\
0.131 \\
0.073 \\
1.000 \\
0.016\end{array}$ \\
\hline
\end{tabular}


of functional QoL of Group II had decreased variable, which shows that the patient is satisfied with the delayed dental implant placement. Whereas the score of functional QoL of Group I had a slight decrease in ability to eat specific foodstuff and ability to use opposing tooth efficiently.

Observing the social QoL variables, slight statistically significant differences were observed between the 2 groups. However, the unwanted attention towards missing tooth was above the threshold level among the mean scores of Groups II. It was also observed that Group I subjects possess high scores for items 1, 3, and 5 (Table 1). While, among Group II subjects, the mean scores for item 1 crossed the threshold limit and values remained the same before and after treatment. The reduction was observed in the values of items 3, 4, and 5, in Group II. The social life of Group II has suddenly changed after treatment from bad to better.

In the psychological QoL after treatment, none of patients in Group I, reached the mean score to the threshold level of 3. However, in Group II, the mean score of items covering mouth with hand/handkerchief had decreased. Increased self-confidence and feeling of well-being were observed in both of the groups. Reduction in feeling of ugliness and loss of confidence had been restored. Moreover, the continuous thinking about missing tooth had been reduced to a great extent (Table 1).

For the functional QoL, the mean scores of Group I were significantly lower as compared to that of Group II for overall scores as well as for item; costs of visit to a dentist. Cost of loss of occupational commitments have been equal on both Group I and II. The mean scores of none of the aspects reached to the threshold value of 15 in both of the groups after treatment. It indicated that following treatment, the QoL of patients was well within the normal levels. The overall assessment revealed that the QoL of Group I patients was better as compared to Group II patients; however, only the differences of functional and financial aspects showed a significant difference between the 2 groups (Table 1 ).

The mean scores of Group II were higher than those in Group I, on various issues related to the functional QoL. The ability to eat specific foodstuff such as gram

Table 2 - Functional, social, psychological, and financial quality of life (QoL) before treatment.

\begin{tabular}{|c|c|c|c|c|}
\hline \multirow[t]{2}{*}{ QoL aspects } & Group I (n=8) & Group II $(n=16)$ & \multicolumn{2}{|c|}{ Statistical significance } \\
\hline & \multicolumn{2}{|c|}{ Mean \pm SD } & t & $P$-value \\
\hline \multicolumn{5}{|l|}{ Functional aspect } \\
\hline $\begin{array}{l}\text { Ability to take all kind of food } \\
\text { Disability to speak some particular words/phonetics } \\
\text { Ability to eat specific food stuff } \\
\text { Ability to clean teeth/prosthesis properly } \\
\text { Ability to use opposing tooth efficiently } \\
\text { Total score }\end{array}$ & $\begin{array}{c}1.75 \pm 1.28 \\
2.00 \pm 1.41 \\
2.50 \pm 0.93 \\
1.38 \pm 1.60 \\
2.50 \pm 0.93 \\
10.13 \pm 4.52\end{array}$ & $\begin{array}{l}1.81 \pm 0.54 \\
2.19 \pm 1.80 \\
3.13 \pm 0.96 \\
2.69 \pm 1.62 \\
3.44 \pm 0.73 \\
13.25 \pm 0.93\end{array}$ & $\begin{array}{l}-0.170 \\
-0.257 \\
-1.523 \\
-1.878 \\
-2.720 \\
-2.711\end{array}$ & $\begin{array}{l}0.867 \\
0.800 \\
0.142 \\
0.074 \\
0.013 \\
0.013\end{array}$ \\
\hline \multicolumn{5}{|l|}{ Social aspect } \\
\hline $\begin{array}{l}\text { Unwanted attention towards missing tooth } \\
\text { Reduction in participation in social gatherings } \\
\text { Avoidance by spouse/partner } \\
\text { Recommendations to visit a dentist } \\
\text { Social contacts cutting jokes on missing tooth } \\
\text { Total score }\end{array}$ & $\begin{array}{c}2.88 \pm 1.25 \\
2.50 \pm 0.53 \\
1.88 \pm 1.36 \\
3.00 \pm 0.93 \\
3.00 \pm 0.00 \\
13.25 \pm 2.71\end{array}$ & $\begin{array}{l}3.31 \pm 0.95 \\
2.81 \pm 1.33 \\
2.56 \pm 1.41 \\
2.69 \pm 1.35 \\
2.50 \mathrm{v} 1.51 \\
13.88 \pm 5.88\end{array}$ & $\begin{array}{c}-0.961 \\
-0.635 \\
-1.138 \\
0.585 \\
0.929 \\
-0.284\end{array}$ & $\begin{array}{l}0.347 \\
0.532 \\
0.267 \\
0.564 \\
0.363 \\
0.779\end{array}$ \\
\hline $\begin{array}{l}\text { Psychological aspect } \\
\text { Feeling of ugliness } \\
\text { Covering mouth with hand/handkerchief } \\
\text { Loss of confidence } \\
\text { Continuous thinking about missing tooth } \\
\text { Fear of hurting gums } \\
\text { Total score }\end{array}$ & $\begin{array}{c}2.25 \pm 1.39 \\
2.38 \pm 1.41 \\
2.63 \pm 1.06 \\
2.25 \pm 0.71 \\
2.88 \pm 1.13 \\
12.38 \pm 3.93\end{array}$ & $\begin{array}{l}3.19 \pm 1.33 \\
3.50 \pm 0.82 \\
2.75 \pm 1.57 \\
2.63 \pm 1.59 \\
2.75 \pm 1.39 \\
14.81 \pm 5.10\end{array}$ & $\begin{array}{c}-1.607 \\
-2.494 \\
-0.202 \\
-0.632 \\
0.220 \\
-1.183\end{array}$ & $\begin{array}{l}0.122 \\
0.021 \\
0.842 \\
0.534 \\
0.828 \\
0.250\end{array}$ \\
\hline \multicolumn{5}{|l|}{ Financial aspect } \\
\hline $\begin{array}{l}\text { Expenditure on dental prosthesis } \\
\text { Cost of visits to a dentist } \\
\text { Cost of taking special diets } \\
\text { Cost of oral care and maintenance of oral hygiene } \\
\text { Cost of loss of occupational commitments } \\
\text { Total score }\end{array}$ & $\begin{array}{l}0.75 \pm 1.49 \\
1.75 \pm 1.91 \\
1.50 \pm 1.77 \\
2.38 \pm 1.30 \\
2.25 \pm 0.71 \\
8.63 \pm 3.66\end{array}$ & $\begin{array}{c}1.88 \pm 1.96 \\
3.19 \pm 0.75 \\
2.88 \pm 1.36 \\
2.88 \pm 0.96 \\
2.63 \pm 1.50 \\
13.44 \pm 4.27\end{array}$ & $\begin{array}{l}-1.424 \\
-2.673 \\
-2.112 \\
-1.070 \\
-0.666 \\
-2.718\end{array}$ & $\begin{array}{l}0.169 \\
0.014 \\
0.046 \\
0.296 \\
0.513 \\
0.013\end{array}$ \\
\hline
\end{tabular}


and peanut was most severely affected. The item wise comparison revealed statistically significant differences only for the item "the ability to use opposing tooth efficiently". In Group II, the tooth was missing since a long time as compared to Group I, so the opposing tooth was not able to grind or chew food efficiently. The total scores for the functional aspects were $10.13 \pm 4.52$ in Group I and $13.25 \pm 0.93$ in Group II, thereby showing a statistically significant difference between the 2 groups (Table 2). The mean threshold of 3.00 was crossed for items 3 and 5 by the subjects of Group II, which indicated that the ability to eat specific foodstuff and using the opposing tooth was severely impaired in Group II subjects.

In the context of the psychological QoL before the treatment, no statistically significant difference could be seen between the 2 groups, apart from item 2 (covering mouth with hand/handkerchief). However, the threshold of 3 was crossed by Group II subjects for 2 items; 1 (feeling of ugliness) and 2 (covering mouth with hand/handkerchief). Thus, the loss of the tooth for the subjects in both of the groups had a bad impact on their psychological QoL (Table 2).

Considering the financial QoL before treatment, a statistically significant difference was seen between 2 groups before treatment. Item 2 (costs of visiting a dentist) and 3 (costs of taking special diets) in Group II subjects showed higher scores as compared to Group I subjects. The patient reported that the missing tooth increased the cost of special diets in the form of juices, fruits, and so forth. However, the threshold

Table 3 - Summary of results of pre-treatment quality of life (QoL).

\begin{tabular}{lcccc}
\hline QoL aspect & \multicolumn{2}{c}{ Group I $(\mathbf{n}=8)$} & Group II $(\mathbf{n}=16)$ & \multicolumn{2}{c}{ Statistical significance } \\
& \multicolumn{2}{c}{ Mean \pm SD } & $\mathbf{t}$ & $P$-value \\
\hline Functional & $10.13 \pm 4.52$ & $13.25 \pm 0.93$ & -2.711 & 0.013 \\
Social & $13.25 \pm 2.71$ & $13.88 \pm 5.88$ & -0.284 & 0.779 \\
Psychological & $12.38 \pm 3.93$ & $14.81 \pm 5.10$ & -1.183 & 0.250 \\
Financial & $8.63 \pm 3.66$ & $13.44 \pm 4.27$ & -2.718 & 0.013 \\
Total score & $44.38 \pm 11.45$ & $55.38 \pm 14.64$ & 1.854 & 0.077 \\
\hline
\end{tabular}

Table 4 - Summary of results of post-treatment quality of life (QoL).

\begin{tabular}{|c|c|c|c|c|}
\hline \multirow[t]{2}{*}{ QoL aspect } & Group I $(n=8)$ & Group II $(n=16)$ & \multicolumn{2}{|c|}{ Statistical significance } \\
\hline & \multicolumn{2}{|c|}{ Mean \pm SD } & $\mathrm{t}$ & $P$-value \\
\hline Functional & $8.13 \pm 3.44$ & $12.25 \pm 1.57$ & -4.081 & 0.000 \\
\hline Social & $10.88 \pm 3.04$ & $10.44 \pm 3.22$ & 0.319 & 0.753 \\
\hline Psychological & $11.25 \pm 3.88$ & $12.88 \pm 3.58$ & -1.021 & 0.318 \\
\hline Financial & $7.75 \pm 3.01$ & $11.44 \pm 3.37$ & -2.614 & 0.016 \\
\hline Total score & $38.00 \pm 9.67$ & $47.00 \pm 8.87$ & 2.276 & 0.033 \\
\hline
\end{tabular}

of 3.0 was crossed by Group II subjects only for item 2 (costs of visiting a dentist), as most of the patients had already undergone prosthesis or visited the dentist frequently. The results of pre-treatment QoL showed that in Group II, the functional $(p=0.013)$ and financial $(p=0.013)$ QoL were affected more severely as compared to Group I (Table 2).

Table 3 and Table 4 have shown the results of preand post-treatment on the QoL. Whereas, Table 5 has shown the comparison of change observed among both the groups after treatment.

Discussion. The mean scores of Groups II were higher than those in Group I, on various issues related to the functional QoL. The results of the present study have shown no statistically significant differences were observed between the 2 groups regarding the social QoL before the treatment. However, it was seen that among Group I subjects, the scores were too high (at threshold of 3.00) for item 4 and 5 as compared to Group I (Table 2). The affected tooth in a short span of time attracted the attention of the spouse/partner/ people, which resulted in the suggestions or advice to visit dentist to restore the tooth or people might make fun of it. Among Group II subjects, the mean scores for item 1 crossed the threshold limit because people are often asked when he/she will replace the missing tooth in social gatherings. Similar were the results of the study which was studied with a social perspective. ${ }^{10}$ It highlights that policymakers must consider the oral health inequalities when devising an agenda for the dental services, in the form of policies.

No statistically significant difference was found between the 2 groups but the scores of Group II subjects showed a more severe effect on the quality of psychological life because of the tooth loss. Similarly, the study provides that the psychosocial behavior of the individuals gets impacted by the tooth loss and untreated decay, reducing the self-esteem of an individual. ${ }^{11}$ The mean scores of Group I subjects were lower than that of Group II subjects for all the aspects of QoL and the total scores; although, there was no statistically significant difference between the 2 groups. ${ }^{12}$ The difference in the financial QoL was dependent on the special type of diet which was taken following the procedure.

There are numerous risk elements for both endodontic treatment and implant, which are needed to be considered during diagnosis, screening, and treatment planning. ${ }^{13-24}$ The current theory of implant dentistry is not restricted only to the basic desires, but also encompasses cosmetic or aesthetic corrections and alterations to improve the self-esteem, self-reliance, and self-confidence. The aesthetic success of therapy has 
Table 5 - Comparison of change after treatment in 2 groups.

\begin{tabular}{|c|c|c|c|c|c|c|}
\hline \multirow[t]{2}{*}{ Aspect } & \multicolumn{3}{|c|}{ Group I $(n=8)$} & \multicolumn{3}{|c|}{ Group II $(n=16)$} \\
\hline & Mean \pm SD & $\mathbf{t}$ & $P$-value & Mean $\pm S D$ & $\mathrm{t}$ & $P$-value \\
\hline Ability to take all kind of food & $0.875 \pm 1.356$ & 1.825 & 0.111 & $0.063 \pm 0.574$ & 0.436 & 0.669 \\
\hline Disability to speak some particular words/phonetics & $0.375 \pm 0.518$ & 2.049 & 0.080 & $-0.063 \pm 0.854$ & -0.293 & 0.774 \\
\hline Ability to eat specific food stuff & $0.250 \pm 0.463$ & 1.528 & 0.170 & $0.313 \pm 0.479$ & 2.611 & 0.020 \\
\hline Ability to clean teeth/prosthesis properly & $0.250 \pm 0.463$ & 1.528 & 0.170 & $0.688 \pm 0.479$ & 5.745 & 0.000 \\
\hline Ability to use opposing tooth efficiently & $0.250 \pm 0.463$ & 1.528 & 0.170 & $0 \pm 0$ & - & - \\
\hline Total functional & $2.000 \pm 2.204$ & 2.567 & 0.037 & $1.000 \pm 1.095$ & 3.651 & 0.002 \\
\hline Unwanted attention towards missing tooth & $0.500 \pm 0.535$ & 2.646 & 0.033 & $0 \pm 0$ & - & - \\
\hline Reduction in participation in social gatherings & $0.250 \pm 0.463$ & 1.528 & 0.170 & $0.375 \pm 0.500$ & 3.000 & 0.009 \\
\hline Avoidance by spouse/partner & $0.375 \pm 0.518$ & 2.049 & 0.080 & $1.188 \pm 1.471$ & 3.230 & 0.006 \\
\hline Recommendations to visit a dentist & $0.625 \pm 0.916$ & 1.930 & 0.095 & $1.125 \pm 1.500$ & 3.000 & 0.009 \\
\hline Social contacts cutting jokes on missing tooth & $0.625 \pm 0.518$ & 3.416 & 0.011 & $0.750 \pm 1.000$ & 3.000 & 0.009 \\
\hline Total social & $2.375 \pm 1.847$ & 3.637 & 0.008 & $3.438 \pm 4.457$ & 3.085 & 0.008 \\
\hline Feeling of ugliness & $-\quad \quad-$ & - & - & $0.563 \pm 0.512$ & 4.392 & 0.001 \\
\hline Covering mouth with hand/handkerchief & $0.375 \pm 0.518$ & 2.049 & 0.080 & $0.500 \pm 0.516$ & 3.873 & 0.002 \\
\hline Loss of confidence & $0.250 \pm 0.463$ & 1.528 & 0.170 & $0.375 \pm 0.500$ & 3.000 & 0.009 \\
\hline Continuous thinking about missing tooth & $0.250 \pm 0.463$ & 1.528 & 0.170 & $0.125 \pm 0.806$ & 0.620 & 0.544 \\
\hline Fear of hurting gums & $0.125 \pm 0.641$ & 0.552 & 0.598 & $0.375 \pm 1.025$ & 1.464 & 0.164 \\
\hline Total psychological & $0.125 \pm 0.354$ & 1.000 & 0.351 & $1.938 \pm 1.948$ & 3.978 & 0.001 \\
\hline Expenditure on dental prosthesis & $1.125 \pm 1.246$ & 2.553 & 0.038 & $0.375 \pm 0.500$ & 3.000 & 0.009 \\
\hline Cost of visits to a dentist & $0.125 \pm 0.354$ & 1.000 & 0.351 & $0.375 \pm 0.500$ & 3.000 & 0.009 \\
\hline Cost of taking special diets & $0.375 \pm 0.744$ & 1.426 & 0.197 & $0.813 \pm 0.750$ & 4.333 & 0.001 \\
\hline Cost of oral care and maintenance of oral hygiene & $0.250 \pm 0.463$ & 1.528 & 0.170 & $-0.063 \pm 0.443$ & -0.565 & 0.580 \\
\hline Cost of loss of occupational commitments & $0.125 \pm 0.354$ & 1.000 & 0.351 & $0.500 \pm 0.516$ & 3.873 & 0.002 \\
\hline Total financial & $0.875 \pm 0.835$ & 2.966 & 0.021 & $2.000 \pm 1.789$ & 4.472 & 0.000 \\
\hline Overall total & $6.375 \pm 4.809$ & 3.750 & 0.007 & $8.375 \pm 6.850$ & 4.891 & 0.000 \\
\hline
\end{tabular}

become the foremost concern among patients and is considered as a part of the QoL, as the success of dental implants has improved beyond doubt. ${ }^{15,16,18-21,23,24}$ Dental implants are a successful alternative to conventional fixed and removable prostheses in terms of aesthetics, comfort, chewing, and phonetics. Implant supported rehabilitation significantly upsurges the QoL, self-confidence, and self-reliance among the patients by giving them more comfort and masticatory efficiency. ${ }^{25}$

The results have concluded that both the groups showed more or less similar results, but Group I was slightly better than Group II. This is because the majority of the immediate implant loadings were carried out in the anterior aesthetic zone. However, immediate dental implants were not possible in all patients due to the financial reasons. The long-term survival rate was not concluded, due to small sample size and short duration of the study. Moreover, the other short comings observed in the study include the region restriction, which may have limited the study reach.

One of the major limitations of the study is the use of convenience sampling technique; therefore, the findings could not be generalized to other populations. The study failed to obtain data from patients attending the clinic randomly because of incomplete databases. Thereby, future studies using prospective design should include equal sample sizes for both control and experimental group based on complete databases. It is also possible that variables concerned in this study might be inflated by the questionnaire specific method variance because the questionnaire was self-administered. The implant size plays an important part in its success, which has not been focused in the present study. The present study have used different sizes of implants; however, the bone type was not considered for analyzing the success of implant. There is a significant influence of bone type on the long-term success of the implant. Additionally, true randomization for this study was not feasible because the baseline, pre-treatment, and QoL was significantly different.

In conclusion, future studies need to undertake such follow-ups to gain better understanding of the immediate and delayed implant loading into the extracted site and its effect on the QoL in pre- and post- 
insertion period. Moreover, unlike this study, future studies need to assess the external validity by applying same questions to dental patients in different centers and other cities in Kingdom of Saudi Arabia.

Acknowledgment. The authors gratefully acknowledge with thanks DSR technical and financial support.

\section{References}

1. Allen PF. Assessment of oral health related quality of life. Health Qual Life Outcomes 2003; 1: 40.

2. Heo Y, Heo S, Chang M, Park J. The patients' satisfaction following implant treatment. J Korean Acad Prosthodont 2008; 46: 569-576.

3. Schropp L, Isidor F, Kostopoulos L, Wenzel A. Patient experience of, and satisfaction with, delayed-immediate vs. delayed single-tooth implant placement. Clin Oral Implants Res 2004; 15: 498-503.

4. Sonoyama W, Kuboki T, Okamoto S, Suzuki H, Arakawa $\mathrm{H}$, Kanyama M, et al. Quality of life assessment in patients with implant-supported and resin-bonded fixed prosthesis for bounded edentulous spaces. Clin Oral Implants Res 2002; 13 : 359-364.

5. Singh M, Kumar L, Anwar M, Chand P. Immediate dental implant placement with immediate loading following extraction of natural teeth. Natl J Maxillofac Surg 2015; 6: 252-255.

6. Cosola S, Marconcini S, Giammarinaro E, Poli GL, Covani $\mathrm{U}$, Barone A. Oral health-related quality of life and clinical outcomes of immediately or delayed loaded implants in the rehabilitation of edentulous jaws: a retrospective comparative study. Minerva Stomatol 2018; 67: 189-195.

7. Peñarrocha-Oltra D, Covani U, Peñarrocha-Diago $M$, Peñarrocha-Diago M. Immediate loading with fixed full-arch prostheses in the maxilla: review of the literature. Med Oral Patol Oral Cir Bucal 2014; 19: e512-e517.

8. Romanos G, Froum S, Hery C, Cho SC, Tarnow D. Survival rate of immediately vs delayed loaded implants: analysis of the current literature. J Oral Implantol 2010; 36: 315-324.

9. Fareed WM. Immediate versus delayed dental implants. $\mathrm{Br}$ Biotechnol J 2015; 11: 1-7.

10. Herkrath FJ, Vettore MV, Werneck GL. Contextual and individual factors associated with dental services utilisation by Brazilian adults: A multilevel analysis. PLoS One 2018; 13: e0192771.

11. Kaur P, Singh S, Mathur A, Makkar DK, Aggarwal VP, Batra $\mathrm{M}$, et al. Impact of Dental Disorders and its Influence on Self Esteem Levels among Adolescents. J Clin Diagn Res 2017; 11 : ZC05-ZC08.
12. Mary AV, Mahendra J, John J, Moses J, Ebenezar AVR, Kesavan R. Assessing Quality of Life using the Oral Health Impact Profile (OHIP-14) in Subjects with and without Orthodontic Treatment need in Chennai, Tamil Nadu, India. J Clin Diagn Res 2017; 11: ZC78-ZC81.

13. Butterworth CJ, Baxter AM, Shaw MJ, Bradnock G. The provision of dental implants in the National Health Service Hospital dental services--a national questionnaire. Br Dent J 2001; 190: 93-96.

14. Conte GJ, Rhodes P, Richards D, Kao RT. Considerations for anterior implant esthetics. J Calif Dent Assoc 2002; 30 : 528-534.

15. Marius HS. The timing of dental implant loading. A literature review. Research_Dental Implant Loading 2010; 3: 06-16.

16. Abu Hantash RO, Al-Omiri MK, Al-Wahadni AM. Psychological impact on implant patients' oral health-related quality of life. Clin Oral Implants Res 2006; 17: 116-123.

17. August M, Chung K, Chang Y, Glowacki J. Influence of estrogen status on endosseous implant osseointegration. J Oral Maxillofac Surg 2001; 59: 1285-1289; discussion 1290-1.

18. Awad MA, Locker D, Korner-Bitensky N, Feine JS. Implants provide better health-related quality of life than conventional treatment for edentulous patients. J Den Res 2000; 79: 1659-1663.

19. Doyle SL, Hodges JS, Pesun IJ, Law AS, Bowles WR. Prospective cross-sectional comparison of initial nonsurgical endodontic treatment and single-tooth implants. Compend Contin Educ Dent 2007; 28: 296-301.

20. Iqbal MK, Kim S. A review of factors influencing treatment planning decisions of single-tooth implants versus preserving natural teeth with nonsurgical endodontic therapy. $J$ Endod 2008; 34: 519-529.

21. McDermott NE, Chuang SK, Woo VV, Dodson TB. Complications of dental implants: identification, frequency, and associated risk factors. Int J Oral Maxillofac Implants 2003; 18: 848-855.

22. Morris HF, Ochi S, Winkler S. Implant survival in patients with type 2 diabetes: placement to 36 months. Ann Periodontol 2000; 5: 157-165.

23. Torabinejad M, Goodacre CJ. Endodontic or dental implant therapy: the factors affecting treatment planning. J Am Dent Assoc 2006; 137: 973-977; quiz 1027-1028.

24. Vehemente VA, Chuang SK, Daher S, Muftu A, Dodson TB. Risk factors affecting dental implant survival. J Oral Implantol 2002; 28: 74-81.

25. Raphael D, Brown I, Renwick R, Rootman I. Quality of life theory and assessment: what are the implications for health promotion [Issues in Health Promotion Series]. Toronto (CN): University of Toronto, Centre for Health Promotion; 1994. 